\title{
Dyspnoea: Pathophysiology and a clinical approach
}

\author{
C B I Coccia, ${ }^{1 \star}$ MB ChB; G H Palkowski, ${ }^{1 *} \mathrm{MB}$ ChB; B Schweitzer, ${ }^{2} \mathrm{MB}$ ChB, FCFP (SA); T Motsohi, ${ }^{2}$ MB ChB, FCFP (SA); \\ N A B Ntusi, ${ }^{1}$ FCP (SA), DPhil \\ ${ }^{1}$ Division of Cardiology, Department of Medicine, Faculty of Health Sciences, University of Cape Town and Groote Schuur Hospital, Cape Town, \\ South Africa \\ ${ }^{2}$ Division of Family Medicine, School of Public Health and Family Medicine, Faculty of Health Sciences, University of Cape Town, South Africa \\ ${ }^{\star}$ Joint first author
}

Corresponding author: N A B Ntusi (ntobeko.ntusi@gmail.com)

\begin{abstract}
Dyspnoea, also known as shortness of breath or breathlessness, is a subjective awareness of the sensation of uncomfortable breathing. It may be of physiological, pathological or social origin. The pathophysiology of dyspnoea is complex, and involves the activation of several pathways that lead to increased work of breathing, stimulation of the receptors of the upper or lower airway, lung parenchyma, or chest wall, and excessive stimulation of the respiratory centre by central and peripheral chemoreceptors. Activation of these pathways is relayed to the central nervous system via respiratory muscle and vagal afferents, which are consequently interpreted by the individual in the context of the affective state, attention, and prior experience, resulting in the awareness of breathing. The clinical evaluation and approach to the management of dyspnoea are directed by the clinical presentation and underlying cause. The causes of dyspnoea are manifold, and include a spectrum of disorders, from benign to serious and life-threatening entities. The pathophysiology, aetiology, clinical presentation and management of dyspnoea are reviewed.
\end{abstract}

S Afr Med J 2016;106(1):32-36. DOI:10.7196/SAMJ.2016.v106i1.10324

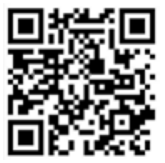

Dyspnoea, often known as shortness of breath or breathlessness, is a common and often distressing symptom reported by patients, and accounts for nearly half of hospital admissions in tertiary centres. ${ }^{[1]}$ As dyspnoea is a symptom and not a sign, the patient experiences it subjectively. Dyspnoea varies greatly among individuals exposed to the same stimuli or with similar pathologies. This differential experience of the condition emanates from interactions among multiple physiological, psychological, social and environmental factors that induce secondary physiological and behavioural responses. $^{[2]}$

Dyspnoea not only manifests with respiratory difficulty that embarrasses and limits the patient, but often presents a diagnostic challenge for the busy clinician. In the evaluation and management of a patient with breathlessness, a comprehensive understanding of the pathophysiology of dyspnoea is essential. A structured clinical approach based on a thorough medical history and clinical examination is key to making the correct diagnosis. Special investigations play secondary and supplementary roles in the diagnosis; they are guided by the history and examination and may be useful in confirming the clinical suspicion of the physician. Disappointingly for both doctors and patients, even when the cause of dyspnoea has been determined, the symptoms may persist despite optimal therapy.

\section{Definition}

Dyspnoea is defined as 'a subjective experience of breathing discomfort that consists of qualitatively distinct sensations that vary in intensity', and may either be acute or chronic. ${ }^{[1]}$ The distinct sensations often reported by patients include effort/work of breathing, chest tightness, and air hunger (a feeling of not enough air on inspiration). Dyspnoea should be assessed by the intensity of these sensations, the degree of distress involved, and its burden or impact on instrumental activities of daily living. Dyspnoea is a normal symptom of heavy exertion but may be pathological if it occurs in unexpected situations. It derives from interactions among multiple physiological, psychological, social, and environmental factors, and may induce secondary physiological and behavioural responses. Its management typically depends on the underlying cause.

\section{Pathophysiology}

Dyspnoea is a complex symptom that arises from physiological impairment and alerts one to the possibility of threatened homeostasis. The discomfort primarily occurs as a result of either cardiovascular or respiratory system compromise, but may also be attributed to metabolic derangements, neuromuscular disorders or psychogenic conditions. The condition is perceived as increased respiratory work/effort, tightness, or air hunger, which are caused by pulmonary ventilation not matching the drive to breathe. ${ }^{[1,3]}$ The dissociation between pulmonary ventilation and respiratory drive arises from a mismatch between afferent receptors in the airways, lungs and chest wall structures, and central respiratory motor activity. Physiological pathways lead to shortness of breath via specific acid-sensing ion channels, mechanoreceptors and lung receptors located in different zones of the respiratory apparatus. Chemoreceptors in the carotid bodies and medulla supply information with regard to the blood gas levels of $\mathrm{O}_{2}$, $\mathrm{CO}_{2}$ and $\mathrm{H}^{+}$. In the lungs, juxtacapillary receptors are sensitive to pulmonary interstitial oedema, while stretch receptors signal bronchoconstriction. Muscle spindles in the chest wall signal the stretch and tension of the respiratory muscles. Efferent signals are the motor neuronal signals descending to the respiratory muscles, the most important being the diaphragm.

Three main components contribute to dyspnoea: afferent signals, efferent signals, and central information processing. The central processing in the brain compares the afferent and efferent signals and dyspnoea results when a mismatch occurs between the two, such as when the need for ventilation (afferent signalling) is not being met by physical breathing (efferent signalling). The afferent receptors allow the brain to assess whether the efferent or motor commands to the ventilatory muscles are effective, meeting 
the required demands of airway pressure, air flow, and/or lung movement. When these respond inappropriately to the command, the intensity of the dyspnoea increases. ${ }^{[4]}$ The sensory cortex is simultaneously activated when motor signals are sent to the chest wall, resulting in the conscious sensation of muscular effort and breathlessness. ${ }^{[5]}$ There is also a strong psychological component to dyspnoea, as some people may become aware of their breathing in such circumstances but not experience the distress typical of the condition.

\section{Causes of dysinoea}

Dyspnoea is primarily of respiratory or cardiac origin, with almost $90 \%$ of all cases being due to asthma, heart failure, myocardial ischaemia, chronic obstructive pulmonary disease (COPD), pneumonia, and psychogenic disorders. ${ }^{[6]}$ In the South African (SA) context, where there is a high burden of HIV infection, a broader differential needs to be incorporated that includes infectious diseases such as tuberculosis, Pneumocystis pneumonia, aspergillosis and acute infective exacerbations of bronchiectasis. Furthermore, due to the high prevalence of interpersonal violence in SA, a significant proportion of patients presenting to emergency centres have dyspnoea related to trauma, with the cause dependent on the mechanism of injury and organ system involved. Table 1 highlights important causes of dyspnoea.

\section{Clinical evaluation}

A patient presenting with dyspnoea often complains of difficulty breathing or chest discomfort and may present to a general practitioner, community health centre or emergency centre. A problematic aspect of the clinician-patient interface is the complicated use of language in articulating the patient's experience, which may be a manifestation of biological, social and psychological challenges facing an individual. A biopsychosocial classification of dyspnoea follows the acronym DYSPNEA:

D: Depression

Y: Yearning for peace, forgiveness, etc.

$S$ : Social issues

P: Physical problems, pain

$\mathrm{N}$ : Non-acceptance or spiritual/existential distress

E: Economic or financial distress

A: Anxiety or anger.

There is always a certain degree of concern with regard to understanding the different types of dyspnoea that stem from different neurophysiological pathways (sequentially or in parallel) and viewing them as socioculturally diverse ways of describing the same neurophysiological phenomenon.

In the initial assessment/triage it is essential to establish the degree of urgency by determining the duration of the dyspnoea, the severity of the symptoms and whether the condition is acute or chronic. It is imperative to detect warning signs that require immediate attention, as the patient may have a life-threatening cause of dyspnoea. These 'red flags' include hypotension, a high respiratory rate, an altered mental status, hypoxia, cyanosis, stridor, breathing effort without air movement, chest wall retractions, tracheal deviation and unilateral breath sounds (underlying pneumothorax), and an unstable arrhythmia (Table 2). ${ }^{[7]}$ The presence of any of these mandates emergency assessment of the patient, including supplementation of oxygen and consideration of endotracheal intubation.

With regard to the clinical evaluation, there are two major categories of patients: those with new onset of breathing discomfort for whom the underlying cause of dyspnoea has not yet been determined; and those with known cardiovascular,

\section{Table 1. Causes of dyspnoea}

\begin{tabular}{|c|c|}
\hline System & Pathology \\
\hline Cardiac & $\begin{array}{l}\text { Arrhythmia } \\
\text { Atrial fibrillation } \\
\text { Sinus tachycardia } \\
\text { Sick sinus syndrome/bradycardia } \\
\text { Ventricular tachycardia/fibrillation } \\
\text { Myocardial } \\
\text { Cardiomyopathy } \\
\text { Hypertensive heart disease } \\
\text { Congestive cardiac failure } \\
\text { Myocarditis } \\
\text { Coronary vessels } \\
\text { Myocardial ischaemia } \\
\text { Acute myocardial infarction } \\
\text { Chronic ischaemic myocardial dysfunction } \\
\text { Valvular } \\
\text { Aortic stenosis/regurgitation } \\
\text { Mitral stenosis/regurgitation } \\
\text { Tricuspid regurgitation/stenosis } \\
\text { Pulmonic regurgitation/stenosis } \\
\text { Pericardial } \\
\text { Pericarditis } \\
\text { Pericardial effusion } \\
\text { Pericardial tamponade } \\
\text { Pericardial constriction } \\
\text { Congenital } \\
\text { Atrial septal defect } \\
\text { Tetralogy of Fallot }\end{array}$ \\
\hline Respiratory & $\begin{array}{l}\text { Obstructive } \\
\text { Asthma } \\
\text { Chronic obstructive pulmonary disease } \\
\text { Bronchitis } \\
\text { Bronchiectasis } \\
\text { Bronchiolitis obliterans } \\
\text { Intrabronchial neoplasm } \\
\text { Tracheomalacia } \\
\text { Obstructive sleep apnoea } \\
\text { Restrictive } \\
\text { Interstitial lung disease } \\
\text { Sarcoidosis } \\
\text { Kyphoscoliosis } \\
\text { Obesity } \\
\text { Pleural disease/effusion } \\
\text { Pneumothorax } \\
\text { Alveolar } \\
\text { Bronchoalveolar carcinoma } \\
\text { Tuberculosis } \\
\text { Bacterial pneumonia } \\
\text { Pneumocystis pneumonia } \\
\text { Eosinophilic pneumonitis } \\
\text { Aspiration } \\
\text { Hypersensitivity pneumonitis } \\
\text { Interstitial } \\
\text { Drugs (methotrexate, amiodarone) } \\
\text { Radiation therapy } \\
\text { Passive congestion/pulmonary oedema } \\
\text { Lymphangitic spread of malignancy } \\
\text { Vascular } \\
\text { Pulmonary embolus (acute/chronic) } \\
\text { Idiopathic pulmonary hypertension }\end{array}$ \\
\hline
\end{tabular}

Continued ... 
Table 1. (continued) Causes of dyspnoea

\begin{tabular}{|c|c|}
\hline System & Pathology \\
\hline Haematological & $\begin{array}{l}\text { Anaemia } \\
\text { Methaemoglobinaemia } \\
\text { Sulfhaemoglobinaemia } \\
\text { Carbon monoxide poisoning } \\
\text { Thrombotic thrombocytopenic purpura }\end{array}$ \\
\hline Abdominal & $\begin{array}{l}\text { Ascites } \\
\text { Gastro-oesophageal reflux disease } \\
\text { Peptic ulcer disease }\end{array}$ \\
\hline Metabolic & $\begin{array}{l}\text { Thyroid disease } \\
\text { Cushing's syndrome }\end{array}$ \\
\hline Psychogenic & Anxiety and panic attacks \\
\hline Neurological & $\begin{array}{l}\text { Amyotropic lateral sclerosis } \\
\text { Polio } \\
\text { Other acute viral anterior horn infections } \\
\text { Guillain-Barré syndrome } \\
\text { Myasthenia gravis } \\
\text { Paraneoplastic myasthenia syndrome }\end{array}$ \\
\hline Physiological & $\begin{array}{l}\text { Exercise } \\
\text { Normal ageing } \\
\text { Deconditioning } \\
\text { Obesity }\end{array}$ \\
\hline $\begin{array}{l}\text { Uncommon } \\
\text { causes }\end{array}$ & $\begin{array}{l}\text { Pulmonary contusion } \\
\text { Angio-oedema } \\
\text { Trauma } \\
\text { Foreign body aspiration } \\
\text { Retrosternal goitre } \\
\text { Vocal cord dysfunction } \\
\text { Pulmonary hypertension } \\
\text { Hepatopulmonary syndrome } \\
\text { Pulmonary arteriovenous malformations } \\
\text { Mesothelioma } \\
\text { Pleuritis } \\
\text { Haemothorax } \\
\text { Cardiac drugs } \\
\text { Superior vena cava syndrome } \\
\text { Pulmonary leukostasis } \\
\text { Tetanus } \\
\text { Botulism } \\
\text { Anaphylaxis }\end{array}$ \\
\hline
\end{tabular}

respiratory, or neuromuscular disease who are experiencing worsening symptoms. For the former, evaluation is focused on discovering an underlying abnormality or diagnosis; for the latter, the goal is to discern whether there is deterioration of a known disorder or emergence of a new problem. In a patient with new onset of dyspnoea, the history and physical examination remain the mainstay of diagnostic evaluation. Among those for whom diagnosis remains elusive, specialist referral should be considered (e.g. to a pulmonologist, cardiologist, or multidisciplinary dyspnoea clinic), which will probably lead to identification and successful management of the underlying cause. Psychogenic dyspnoea may be a significant challenge for primary care physicians. The typical scenario is a young person without a notable medical history, with normal oxygen saturation in room air, who complains of breathlessness and tingling around the mouth, fingers and toes. Psychogenic dyspnoea responds well to reassurance (and acknowledgement of the underlying problem).
Table 2. 'Red flags' for serious forms of dyspnoea

Hypotension
Respiratory rate $>40$ breaths/minute
Altered mental status
Hypoxia
Cyanosis
Stridor
Breathing effort without air movement
Tracheal deviation with unilateral breath sounds
Unstable arrhythmia

\section{Medical history}

A complete history should emphasise any coexisting cardiac and pulmonary comorbidities and symptoms, as the cardiac and pulmonary systems comprise the most common causes of dyspnoea. Moreover, the history should determine the character, onset, duration, associations, severity, relation to exertion and any exacerbating/relieving factors. The presence of cough may imply asthma or chest infection, and cough combined with a change in the appearance of the sputum may be related to an exacerbation of COPD. Chest pain during dyspnoea may be caused by cardiac conditions or pleural disease (the description of the quality of the chest pain is useful). Pleuritic chest pain results from pericarditis, pneumonia, pulmonary embolism, pneumothorax, or pleuritis. Chest pain almost always occurs in spontaneous pneumothorax, while dyspnoea is the second most common symptom. Anginal chest pain accompanied by shortness of breath may signify ischaemia associated with left ventricular dysfunction. Sudden shortness of breath at rest suggests pulmonary embolism or pneumothorax. Spontaneous pneumothorax should be considered in patients with COPD, cystic fibrosis, or AIDS. A history of scuba diving may suggest barotrauma. Vehicle airbag trauma has been reported to cause pneumothorax. The clinician should note a history of penetrating or non-penetrating trauma. Severe respiratory distress continuing over 1 - 2 hours suggests congestive cardiac failure (CCF) or asthma. The presence of comorbidities such as hypertension, hyperlipidaemia, diabetes mellitus, and obstructive sleep apnoea increase the likelihood of developing CCF.

Elements of the social history include smoking, alcohol use and illicit drug use. A family history of coronary artery disease, dilated cardiomyopathy, and sudden cardiac death may provide important information regarding the possible aetiology of CCF. Dyspnoea may also present as orthopnoea (breathlessness on assuming the supine position) and paroxysmal nocturnal dyspnoea (attacks of breathlessness that occur at night and may awaken the sleeping patient). Patients with CCF tend to increase the number of pillows on which they sleep to avoid symptoms of orthopnoea: the number of pillows is a marker of the severity of heart failure. Advanced or end-stage heart failure can present with an abnormal pattern of breathing characterised by periods of hyperapnoea and CheyneStokes respiration, which is a marker of poor prognosis.

Non-respiratory causes of dyspnoea should be considered, including anaemia, acidosis and drug poisoning. The attending physician should enquire about indigestion or dysphagia, which may indicate gastro-oesophageal reflux or aspiration. Anxiety symptoms may imply psychogenic causes of dyspnoea, but organic causes should always be excluded first: a diagnosis of hyperventilation syndrome cannot be made before organic disease is ruled out.

Medication use is another important consideration, especially drugs with potential adverse cardiopulmonary effects (e.g. betablockers, eyedrops). Drugs may cause haemolytic anaemia (quinidine 
and penicillin); methaemoglobinaemia (nitrites and nitrates); sulfhaemoglobinaemia (dapsone and sulfonamides); and acute or chronic fibrosis (nitrofurantoin or amiodarone). Aspirin sensitivity is a cause of asthma in a significant number of patients.

\section{Clinical examination}

General appearance and vital signs. To determine the severity of dyspnoea, one should carefully observe respiratory effort, use of accessory muscles, mental status, and ability to speak. Pulsus paradoxus may exist in COPD, asthma, cardiac tamponade or pericardial constriction. Stridor indicates upper airway obstruction. It may be necessary to obtain a rectal temperature to detect fever, as oral airflow may decrease the oral temperature.

Extremities. The lower extremities should be inspected for oedema and any signs suggestive of deep venous thrombosis, and the digits examined for clubbing or cyanosis.

Neck. Distention of the neck veins may imply cor pulmonale caused by severe COPD, CCF, or cardiac tamponade. The thyroid size should be assessed, as CCF may result from hyper- or hypothyroidism. The trachea should be central and the presence of stridor excluded.

Cardiac and pulmonary disease. Palpate the chest for subcutaneous emphysema and crepitus, and percuss for dullness, an indication of consolidation or effusion. Hyper-resonance on percussion suggests pneumothorax or bullous emphysema. The clinician should always auscultate the heart and lungs for murmurs or extra heart sounds; absent breathing sounds may be consistent with pneumothorax or pleural effusion. Wheezing is usually consistent with obstructive lung disease, but can be caused by pulmonary oedema or pulmonary embolism. Rales are present in pulmonary oedema, pneumonia or restrictive lung pathology. A rapid or irregular pulse may signify a dysrhythmia. An S3 gallop suggests left ventricular systolic dysfunction in CCF, while an S4 gallop may indicate left ventricular dysfunction in hypertension or ischaemia. A loud P2 may be heard in patients with pulmonary hypertension or cor pulmonale. Murmurs can be an indirect sign of CCF or valvular heart disease, and distant heart sounds can point to cardiac tamponade.

Abdomen. The clinician should look for hepatomegaly and ascites. Assessing for hepatojugular reflux is a valid bedside maneouvre in the diagnosis of CCF in patients with acute dyspnoea.

\section{Relevant special investigations}

Chest radiography (CXR). This has a great potential in aiding the diagnosis of many lung disorders that cause acute dyspnoea and chest pain. The physician should be aware that the sensitivity of CXR is rather low in the diagnosis of pneumothorax, pleural effusion and pulmonary oedema, particularly in bedside-acquired images. Nevertheless, thoracic imaging by means of CXR plays a crucial role in the diagnostic process, because it allows a panoramic view, at the same time being cost-effective, safe and time saving.

Electrocardiography (ECG). In African patients presenting with heart failure common causes include hypertension (43.2\%), idiopathic dilated cardiomyopathy $(21.0 \%)$, rheumatic heart disease (17.2\%), and ischaemic heart disease (7.7\%). ${ }^{[8]}$ The ECG is unlikely to be normal in the presence of structural heart disease. However, in black patients, ECG abnormalities can occur among those without heart disease; up to $13 \%$ of these patients may present with significant $\mathrm{Q}$ waves in the absence of myocardial ischaemia.

Cardiopulmonary exercise tests. These can be particularly helpful in the evaluation of patients in whom an initial evaluation is unrevealing or in those in whom multiple problems may contribute to dyspnoea. Identifying non-respiratory causes of exercise limitation (e.g. leg discomfort, fatigue or weakness) is important, because these often coexist with breathing discomfort.
The D-dimer. This is a component of the evaluation of patients with suspected pulmonary embolism. As with many screening tests, the sensitivity of $\mathrm{D}$-dimer is much greater than its specificity, and its positive predictive value is poor. Therefore, its primary value is to rapidly identify patients with a low probability of pulmonary embolism, particularly in outpatient settings. There is evidence that its negative predictive value is poor in hospitalised patients, especially after several days of hospitalisation, or in patients $>60$ years of age.

Brain natriuretic peptide (BNP). Routine use of BNP in all patients presenting with acute dyspnoea is not recommended. In acute-care settings such as an emergency department, the sensitivity of BNP or N-terminal (NT)-pro-BNP is substantially higher than its specificity, and its use is greatest for ruling out heart failure as a cause of acute dyspnoea in patients with a low to intermediate pretest probability of heart failure. In general, heart failure is unlikely at BNP values $<100 \mathrm{pg} / \mathrm{mL}$ and is very likely at BNP values $>500 \mathrm{pg} / \mathrm{mL}$.

Point-of-care ultrasound scans and echocardiography. These may aid clinicians in the diagnosis of acute cardiogenic pulmonary oedema. In patients with a moderate to high pretest probability, a point-of-care ultrasound/echocardiogram can be used to strengthen an emergency physician's working diagnosis of acute cardiogenic pulmonary oedema. In patients with a low pretest probability, a negative study can almost exclude the possibility of the condition.

A clinical decision rule (pulmonary embolism rule-out criteria). To exclude pulmonary embolism among patients with a low suspicion a clinical decision rule has been developed. ${ }^{[9]}$ Pulmonary embolism can also be safely excluded on the basis of a Wells score of $\leq 4$, combined with a negative qualitative point-of-care D-dimer test result. ${ }^{[10]}$

\section{Management}

In a patient with dyspnoea, the initial focus should be on optimising treatment of the underlying disease and relieving symptoms.

Supplemental oxygen. Although supplemental oxygen reduces the mortality rate in chronically hypoxaemic patients with COPD, there are conflicting data about its ability to relieve breathlessness. Beneficial effects of oxygen could be related to changes in chemoreceptor stimulation, changes in breathing pattern, and/or stimulation of receptors related to gas flow through the upper airway. Oxygen therapy may be useful for patients with advanced heart or lung disease, in particular those who are hypoxaemic at rest. Long-term oxygen therapy (LTOT) may be of great help in patients with COPD. Patients with stable COPD and a resting $\mathrm{PaO}_{2} \leq 7.3 \mathrm{kPa}$ should be assessed for LTOT. The latter should not be routinely administered to patients who are breathless when there is no evidence of benefit, as it is expensive and may sometimes be associated with increased harm.

Pharmacological therapy. Opioids have been the most widely studied agents in the treatment of dyspnoea. Short-term administration reduces breathlessness in patients with a variety of conditions, including advanced COPD, interstitial lung disease, cancer, and CCF. However, evidence of long-term efficacy is limited and conflicting. Recent evidence-based clinical guidelines recommend that opioids be considered on an individualised basis for palliation of unrelieved dyspnoea in patients with advanced cardiopulmonary disease despite otherwise adequate treatment of the underlying condition, with due consideration to patient history, comorbid conditions, and risk of respiratory depression.

Pulmonary rehabilitation. This is an integral component of the management of patients with chronic lung disease. Among the beneficial effects of pulmonary rehabilitation are a reduction in exertional dyspnoea during exercise and improved exercise tolerance, as well as a decrease in self-reported dyspnoea with activity. Exercise is the main component of pulmonary rehabilitation responsible for these improvements, but it is less clear whether mechanisms leading to improvement in 
dyspnoea are mainly due to improvements in conditioning, pacing of activities, desensitisation to respiratory sensations or affective distress, or a combination of these effects. Evidence that other components of pulmonary rehabilitation (e.g. education to improve inhaler technique, medication adherence, pacing activities, or breathing techniques) ameliorate dyspnoea independent of exercise is inconsistent, but it is likely that individual characteristics, such as motivation, are relevant. In COPD, pulmonary rehabilitation may result in decreased ventilatory requirements and respiratory rate during ambulation, thereby decreasing the risk for developing dynamic hyperinflation. There is evidence that patients with COPD who undergo 6 weeks of exercise training experience comparable small decreases in dyspnoea intensity, regardless of whether or not they demonstrate improved exercise capacity.

Other non-pharmacological approaches. Patients with dyspnoea often report that movement of cool air reduces breathlessness, and laboratory studies have shown that cold air directed on the face decreases dyspnoea induced in healthy individuals. Increased respiratory muscle effort, associated with high ventilatory demand relative to respiratory muscle capacity, may contribute to dyspnoea in many patients with chronic respiratory disease. By reducing the demand on the respiratory muscles, non-invasive ventilation might reduce dyspnoea. However, few studies of non-invasive ventilation have used dyspnoea as an endpoint.

\section{Conclusion}

Dyspnoea is a common and often distressing symptom and a frequent reason for general practitioner and clinic visits. Dyspnoea is symptom, and its experience is subjective and varies greatly among individuals exposed to the same stimuli or with similar pathologies. This differential experience of dyspnoea among individuals emanates from interactions among multiple physiological, psychological, social, and environmental factors that induce secondary physiological and behavioural responses. The management of dyspnoea will depend on the underlying cause.

Funding. This manuscript is not funded. Dr N A B Ntusi acknowledges support from the National Research Foundation and Medical Research Council of South Africa.

\section{References}

1. Parshall MB, Schwartzstein RM, Adams L, et al. An official American Thoracic Society Statement: Update on the mechanisms, assessment, and management of dyspnea. Am J Respir Crit Care Med 2012;185(4):435-453. [http://dx.doi.org/10.1164/rccm.201111-2042ST]

2. Boyars MC, Karnath BM, Mercado AC. Acute dyspnea: A sign of underlying disease. Hosp Phys 2004;40(7):23-27

3. O'Donnell DE, Banzett RB, Carrieri-Kohlman V, et al. Pathophysiology of dyspnea in chronic obstructive pulmonary disease. Proc Am Thor Soc 2007;4(2):145-168. [http://dx.doi.org/10.1513/pats.200611-159CC] Manning HL, Schwartzstein RM. Pathophysiology of dyspnea. N Engl J Med 1995;333:1547-1553 [http://dx.doi.org/10.1056/NEJM199512073332307]

5. Nishino T. Dyspnoea: Underlying mechanisms and treatment. Br J Anaesth 2011;106(4):463-474 [http://dx.doi.org/10.1093/bja/aer040]

6. Zoorob RJ, Campbell JS. Acute dyspnea in the office. Am Fam Phys 2003;68(9):1803-1810.

6. Zoorob RJ, Campbell J. Acute dyspnea in the office. Am Fam Phys 2003;68(9):1803-18
7. Gopal M, Karnath B. Clinical diagnosis of heart failure. Hosp Phys 2009;45(7):9-15.

8. Ntusi NAB, Mayosi BM. Epidemiology of heart failure in sub-Saharan Africa. Expert Rev Cardiovasc Ther 2009;7(2):169-80. [http://dx.doi.org/10.1586/14779072.7.2.169]

9. Singh B, Mommer SK, Erwin PJ, Mascarenhas SS, Parsaik AK. Pulmonary embolism rule-out criteria Singh B, Mommer SK, Erwin PJ, Mascarenhas SS, Parsaik AK. Pulmonary embolism rule-out criteria
(PERC) in pulmonary embolism - revisited: A systematic review and meta-analysis. Emerg Med J (PERC) in pulmonary embolism - revisited: A systematic review and

10. Geersing GJ, Erkens PM, Lucassen WA, et al. Safe exclusion of pulmonary embolism using the Wells rule and qualitative D-dimer testing in primary care: Prospective cohort study. BMJ 2012;345:e6564 [http://dx.doi.org/10.1136/bmj.e6564] 